\title{
R\&D portfolios in environmentally friendly automotive propulsion: Variety, competition and policy implications
}

\author{
Koen Frenken ${ }^{\mathrm{a}, *}$, Marko Hekkert ${ }^{\mathrm{b}}$, Per Godfroij ${ }^{\mathrm{c}}$ \\ ${ }^{a}$ Department of Economic Geography, Urban and Regional Research Centre Utrecht (URU), \\ Faculty of Geographical Sciences, Utrecht University, P.O. Box 80115, NL-3508TC Utrecht, The Netherlands \\ ${ }^{\mathrm{b}}$ Department of Innovation Studies, Copernicus Institute for Sustainable Development and Innovation, \\ Faculty of Geographical Sciences, Utrecht University, P.O. Box 80125, NL-3508TC Utrecht, The Netherlands \\ ${ }^{\mathrm{c}}$ The Netherlands Ministry of Housing, Spatial Planning and the Environment, P.O. Box 20951, \\ NL-2500EZ, The Hague, The Netherlands
}

Received 4 October 2002; received in revised form 30 January 2003; accepted 1 February 2003

\begin{abstract}
In this article, we analyze $\mathrm{R} \& \mathrm{D}$ portfolios in environmentally friendly automotive propulsion including alternative fuel options. We argue that at the current stage of development, substitution of conventional car technology by a new automotive propulsion technology may lead to premature lock-in of suboptimal technology. To avoid such lock-in, one should value the variety of current R\&D activity that enables organizations to learn from multiple options and to create spillovers between options. We further argue that the existence of technological variety is not a sufficient condition to avoid lock-in. Organizational variety is also required to sustain competition and avoid the dominance of few firms that possibly enforce a suboptimal technology within the sector. To assess whether recent developments in $R \& D$ have led to both technological variety and organizational competition, we analyze United States Patent and Trademark Office (USPTO) patents in low-emission vehicles (LEVs) during the period 1980-2001 using entropy statistics. Results show that both technological variety and organizational competition have increased steadily since the early nineties, suggesting that premature lock-in is unlikely to occur. From an
\end{abstract}

* Corresponding author. Tel.: +31-30-253-1625; fax: +31-30-253-6963.

E-mail addresses: k.frenken@geog.uu.nl (K. Frenken),m.hekkert@geog.uu.nl (M. Hekkert), per.godfroij@minvrom.nl (P. Godfroij). 
environmental policy evaluation perspective, we consider the findings as a positive evaluation of the 1990 Californian Low Emission Vehicle program.

(C) 2003 Elsevier Inc. All rights reserved.

Keywords: Technological substitution; Variety; Entropy; Lock-in; Suboptimality; Sustainability; Fuel cell; Electric vehicle; Patent; Californian Low Emission Vehicle program

\section{Introduction}

It is widely acknowledged that car usage leads to a broad range of air emissions that contribute to climate change (carbon dioxide emissions) and smog formation (volatile organic substances, carbon monoxide, and nitrous oxide). Since the 1970s, car manufacturers have been active in $R \& D$ programs that aim to reduce the car emissions with the introduction of more efficient engine technology and more widespread use of catalytic converters. Following the Californian Air Resources Board (CARB) mandate of the Low Emission Vehicle (LEV) program in 1990, automobile manufacturers were stimulated to go much further in their development of efficient, clean, and environmentally friendly products. This program approved standards for low- and zero-emission vehicles (LEVs and ZEVs, respectively) between 1994 and 2003, aiming to ensure the progressive introduction of transitional LEVs, LEVs, and ultra-LEVs into product ranges. Furthermore, the LEV program stated that $2 \%$ of passenger cars produced and offered for sale in California in 1998 should be ZEVs and this percentage was to rise gradually to $10 \%$ in 2003. ${ }^{1}$ As a reaction to the CARB mandates, the industry currently develops three major options for the future car system, which are likely to be among the technologies that compete for substituting the existing internal combustion engine paradigm. The three technologies concern electric vehicles (EVs), hybrid electric vehicles (HEVs), and fuel cell vehicles (FCVs).

In this article, we analyze R\&D portfolios of firms and other organizations in these technologies as evidenced by their patenting activity. The patent analysis that is presented will not only consider the rate of R\&D activity but also its distribution. Using the entropy measure as an indicator of technological variety, we are able to assess whether the recent rise in R\&D activity is heterogeneous or whether technological development is converging towards one dominant technological trajectory. We consider this research question of great importance, since, although a transition towards sustainability is urgently required, one should avoid a premature lock-in within a new trajectory that might, in hindsight and on reflection, prove to be suboptimal. At the current stage of development, we argue that variety is to be preferred over standardization.

\footnotetext{
${ }^{1}$ In 1998, CARB approved new proposals that eliminated the 1998-2003 requirements but led to a strengthening of the regulations after 2004.
} 
A novelty in our study concerns the analysis of variety at both the industry as a whole (entropy) and the individual companies undertaking R\&D (conditional entropy). The twolevel analysis of $R \& D$ activity allows one to observe whether technological variety at the industry level is resulting primarily from divergent company strategies with regard to the technological trajectory explored, or whether technological variety is also present within individual companies reflecting flexible $R \& D$ portfolios. The latter situation is preferable because a premature lock-in is less likely when all actors remain flexible in their choice of technology. Similarly, we analyze organizational competition in terms of variety of organizations that are involved in R\&D. Organizational competition can be indicated by the entropy of the patent shares of organizations, both at the industry level as a whole and the level of individual technologies. In this way, we are able to assess whether organizational competition has increased or decreased, and whether organizational competition takes place primarily between different technologies or also at the level of individual technologies.

The article is organized as follows. In Section 2, we briefly discuss, first, the technological characteristics of the three environmentally friendly automotive propulsion technologies, as well as their strengths and weakness in car performance and environmental benefits. The theory of technological substitution and lock-in is addressed in Section 3, followed by a proposed statistical methodology to analyze technological variety at the industry level and company level in Section 4. In Section 5, we present the data and results of the statistical analysis. Section 6 provides a discussion of the results and indicates further research questions. Finally, Section 7 closes with a reflection on environmental policy and technology policy in light of our findings.

\section{Low-emission vehicles}

Before we discuss the theoretical framework for our analysis, we present a short background on the alternative automotive propulsion technologies that are technically capable of radically reducing exhaust emissions. The technologies selected for analysis in this article were chosen based on a literature search that indicated these technologies as those receiving most attention as emission reducing technologies [1]. The three propulsion technologies are EVs, HEVs, and FCVs.

\subsection{Electric vehicle}

An EV can be defined as a vehicle that is propelled by an electric engine that is powered by a battery. Advantages of electric engines compared to conventional internal combustion engines are threefold: EVs do not emit any emissions during $\mathrm{use}^{2}, \mathrm{EV}_{\mathrm{s}}$ are quiet, and EVs have less moving parts, which reduces the need for maintenance [1].

\footnotetext{
${ }^{2}$ It should be remembered, however, emissions do occur when the electricity to charge the batteries is first produced. These emissions depend on the type of fuel that is used in electricity generation.
} 
A disadvantage of current EV technologies is that the energy supply required to power the vehicle needs to be stored as electricity on board the vehicle. The batteries that are needed for this purpose are expensive, have a short life cycle, and have a limited storage capacity. The range of an EV is therefore much smaller than for vehicles fueled with gaseous or liquid energy carriers. Batteries currently have a recharging time of approximately 6 to 8 hours, which makes these cars less suitable for intensive use. Replacing empty batteries with charged batteries is at present not considered a serious option, mainly because the batteries are too heavy [2].

\subsection{Hybrid electric vehicle}

An HEV is defined as a vehicle that is propelled by an internal combustion engine and an electric engine. An HEV can have serial or parallel propulsion systems depending on the way the combustion engine, electric engine, and the batteries are connected. An HEV can be fueled with conventional or alternative fuels. A serial HEV uses its combustion engine to generate electricity to power the electric engine, which drives the car. Due to this concept, the combustion engine never idles, which reduces emissions, and, moreover, no transmission is necessary because of the similarity of torque demand and delivery [3]. More efficiency is realized by harnessing the kinetic energy generated when the car brakes. A parallel HEV uses a combustion engine to drive the car. This propulsion system also allows regeneration of 'braking energy'. After this energy is stored in a battery, it is used to power the electric engine. The electric engine is used in addition to the internal combustion engine when maximal power is required, for example, in case of acceleration. Compared to a serial system, the parallel system can deliver more power due the simultaneous use of combustion engine and electric engine. The efficiency of an HEV depends on the combination of all subsystems, but finally the efficiency can, theoretically, be twice as high as the efficiency of a combustion engine vehicle [3].

\subsection{Fuel cell vehicle}

An FCV is defined as a vehicle driven by an electric engine that is powered by a fuel cell. The fuel cell converts an energy carrier (e.g., hydrogen) into electricity. Hydrogen can be fueled directly in the vehicle or can be produced on board of the vehicle when other fuels, like gasoline or methanol, are used as fuel.

The FCV has the same advantages as a typical electric engine: the possibility to regenerate 'braking energy', the omission of transmission, and the low noise rate. A major problem is the fueling of the vehicle. If zero emissions are required, the vehicle needs direct fueling with hydrogen since the conversion of hydrogen in the fuel cell only leads to water vapor emissions. The use of hydrogen, however, necessitates large changes in the current fueling infrastructure and, due to its gaseous nature, requires novel on board storage technology. To avoid these problems the vehicle can also be fueled with conventional fuels (gasoline, LPG, or diesel) or alternative fuels (alcohol, natural gas, or methanol). All these fuels need to be converted onboard into hydrogen, which is then used to fuel the fuel cell. Fuel conversion, however, leads to unwelcome emissions and involves a complicated technical process. 
Table 1

Advantages $(+,++,+++)$ and disadvantages $(-,--)$ of EV, HEV, and FCV compared with a conventional ICEV

\begin{tabular}{llllll}
\hline & ICEV & EV & HEV & \multicolumn{2}{l}{ FCV } \\
\cline { 4 - 5 } & & & & Hydrogen & Other \\
\hline Energy & & ++ & + & +++ & ++ \\
Emissions & 0 & + & + & + & + \\
Regeneration & 0 & & & - & 0 \\
Practical use & & 0 & 0 & 0 & 0 \\
Range & 0 & ++ & 0 & ++ & ++ \\
Speed & 0 & -- & 0 & -- & 0 \\
Engine noise & 0 & 0 & & &
\end{tabular}

\subsection{Comparison}

The advantages and the disadvantages of the three different propulsion technologies are presented schematically in Table 1. All characteristics are compared with the internal combustion engine vehicle (ICEV), which explains why no advantages or disadvantages are attributed to ICEV in the table. Table 1 shows that FCV seems to have the best characteristics to become the LEV of the future. The question remains which fuel is best suited for FCV technology. Due to the low radius of action and long recharge times, the EV is a poor contender for the current ICEV status. However, the EV might be the best choice for several niche markets like company cars that do not need long radius of action and are not used during the night (e.g., post delivery cars, airport shuttles, service cars, and shopping cars). The HEV is generally regarded as a transition technology since it can act as a bridging technology between current ICEVs and FCVs.

\section{Technological substitution and increasing returns to adoption}

To assess the current state of development using data on firms' R\&D portfolios, we make use of insights from economics of innovation regarding the logic of technological substitution processes. Traditional economic theory considers the process of technological substitution to be based primarily on a comparison between input costs of different options by profit maximizing firms. A suboptimal choice outcome is excluded theoretically because it is assumed that all firms are fully informed about the costs and benefits of all options. More recently, evolutionary economics emphasizes that markets may select a suboptimal technology as increasing returns to adoption render the process of technology selection path dependent and, to a large extent, an irreversible and unpredictable process [4-10]. 
Evolutionary economists, starting from the work by Arthur [4] and David [5], have put forward two propositions regarding technological substitution processes:

Proposition 1: Technological substitution is not warranted when a superior technology is introduced in the market because the incumbent technology benefits from increasing returns to adoption.

Proposition 2: When technological substitution does take place and several new technologies are competing for dominance, selection of a suboptimal technology is possible due to path dependence of sequential adoption decisions.

\subsection{Proposition 1}

The conservatism of market selection with respect to new technologies is understood as the result of increasing returns to adoption that are associated with an existing technology. Increasing returns to adoption means that the benefits for an individual adopter of a technology increase with the number of fellow adopters of the technology. These benefits come from a variety of sources, including knowledge spillovers, economies of scale, network externalities in distribution networks, and learning-by-using on the side of the users $[4,11]$.

When increasing returns to adoption are apparent, the adoption by a limited number of users of a new and technically superior technology will not automatically lead to technological substitution. A new technology benefits little from increasing returns to adoption contrary to an existing technology adopted by the large majority of firms. This insight leads to the proposition that the likelihood of technological substitution is dependent on, among other factors, the number of players participating in a market. The larger the number of firms in a market, the less probable the introduction of a new and superior technology by a single firm will induce other firms to follow suit [7].

Increasing returns to adoption does not prohibit technological substitution per se. At least two mechanisms can trigger technological substitution. First, actors can coordinate their decision to adopt the new technology when they recognize that coordinated action yields important benefits. In that case, a group of actors simultaneously switches to the new technology and thus collectively reap the benefits of increasing returns to adoption. Coordination of adoption decisions is often observed with the introduction of new technical standards where actors form alliances around common standards [12].

Second, if technologies do not (only) compete on costs but also differ in their performance characteristics, a new technology may successfully be introduced in a market niche that protects it from competition with the old technology. The new technology can then further develop within the niche and replace the old technology by invading the mass market at a later stage. One example is the gradual diffusion of gas turbines at the cost of steam turbines in electricity generation, through the initial creation of a niche associated with the ability of gas turbines to operate with low load factors [13]. Other examples include the introduction of wireless communication technology [14], jet aircraft [15], and energy-efficient lamps [16]. 


\subsection{Proposition 2}

The second proposition holds that during a technological substitution process several new technologies are competing for dominance, and that path dependence of adoption decisions may render the outcome of the competition process suboptimal. This proposition differs from the first proposition in that we are now dealing with a set of new technologies that compete immediately after their introduction rather than a new technology substituting an old technology. Various models, under different behavioral assumptions, show that when technologies are competing under increasing returns, the sequence of adopters determines the final outcome of the selection process, i.e., there is path dependence in technology selection $[4,9,17,18]$. When returns are increasing with the number of adopters of a particular technology, a small degree of dominance of a technology in the early stages becomes selfreinforcing. Consequently, early adoption decisions for one or another technology have a global effect on future adopters that will follow previous decisions and cause a lock-in of an industry within one technology. Importantly, due to high sunk investment in infrastructure and learning curves, the choice of one technology becomes increasingly irreversible over time. Switching costs are positively related to sunk investments and, even when new information concerning the technical optimality of an alternative technology becomes available, switching seldom takes place [5]. This means that early actions taken by various players, including governments, are decisive regarding the long-term future development of an industry.

Equally, recent models of 'herd behavior' in investment support the thesis of lock-in in a suboptimal technology even in the absence of increasing returns to adoption [19,20]. In these models, a collective 'wrong' decision to invest in an inferior project (e.g., adopting an inferior technology) is caused by individual actors keeping information secret from other actors. Yet, each actor also takes into account the public decisions taken by previous adopters. When early adopters erroneously adopt an inferior technology based on their private and partially stochastically generated information, subsequent adopters choose to follow the early adopters even if their private information suggests otherwise.

A similar, older, concept in the economics of innovation and technology management is the concept of a dominant design. Since Abernathy and Utterback [21-23] first developed the concept of a dominant design from a study of the automobile industry in the late seventies, many writers in the field of innovation and technology management consider the concept a useful tool for studying the evolution of technological products. At the heart of dominant design thinking lies the empirical observation that technology evolves by trial and error and thus entails enormous risks for firms engaged in its development. When a technology appears, it is initially unclear what kind of inherent potential it possesses and the needs users have. Through the development of a variety of different designs, the industry learns about the technological potential and user needs of different options, and progressively converges to, and becomes locked in to, one dominant design. The firms that happen to be the producers of the winning designs will flourish while the firms that invested in the failing designs will incur great economic losses and more often than not go out of business in a process of shake-out [24]. 
Well-known examples of industries that became locked in into a dominant design include the Douglas DC3, an all-metal monocoque aircraft design with cantilever wing and a retractable landing gear [25], the QWERTY layout of keyboards [5], and the VHS standard in video computers [4]. A well-researched example of a suboptimal lock-in is the case of light-water nuclear reactors, which are considered by many experts as inferior to gasgraphite nuclear reactors [26]. At the time of competition between the rival designs, however, the U.S. Navy had already built up an important stock of knowledge regarding light-water nuclear technology in submarine technology and was able to convince U.S. government agencies to adopt this technology for nuclear power plants. The subsequent decision to choose light water over gas graphite reactors caused a lock-in into light-water nuclear reactors in the United States and also in Europe at a later stage. Note that the theory of increasing returns does not imply that selection processes typically lead to suboptimality. An example of a technology that locked in but is widely considered acceptable at the time concerns the adoption of the internal combustion engine in early 20th century instead of the rival electric engine and steam engine technologies [11].

\subsection{The case of low-emission vehicles}

Both propositions regarding technological substitutions discussed above apply at least in part to the future of automotive propulsion. The first proposition concerning the difficulty of technological substitution relates to the increasing returns of continued adoption of the conventional internal combustion engine. The current complex of distribution networks covers large parts of the world, while the alternative propulsion technologies in automobiles require the building of a complete new infrastructure or an expensive restructuring of the current network. Consequently, in the case of automotive propulsion, the sources of increasing returns to adoption lie primary in network externalities stemming from geographic coverage of infrastructure [11]. Alternative technologies like the EV, HEV, and FCV all face the problem of high switching costs due to the infrastructural embeddedness of the incumbent technology.

The second proposition relating to the possibility of lock-in into a suboptimal technology also applies to the current competition between alternative propulsion and fuel technologies. Given the current state of knowledge and the early stage of development of alternative technologies, it is hard to claim that one technology is inherently superior to another. Although many observers expect fuel cells to develop into a superior technology given its combination of efficiency and environmental performance, important technological bottlenecks remain. Even if one accepts the claim of superiority of fuel cell technology, the question of the optimal fuel for FCV is still unresolved. It is for these reasons that in the current situation a convergence in $R \& D$ towards one dominant technology may imply a premature lock-in into a technological trajectory, which may, in retrospect, turn out to be suboptimal.

Note that the second proposition only partially applies to the case of environmentally friendly propulsion technologies. The various options are not unrelated technically as it is assumed in the formal models of technology adoption from which the second proposition is 
derived. In Arthur's [4] model of lock-in, for example, it is assumed that an adoption decision only contributes to increasing returns to the one technology adopted. In the case of LEV, however, innovations within one technology class often have technological spillovers to other technologies. The development of EV and HEV, for example, has lead to innovations that benefited the FCV as well. A case in point is the electrical drive train of EV, which overlaps considerably with the ones used in FCV. When two technologies are technologically interrelated, an adoption of one technology contributes to increasing returns of the other, although to a lesser extent. Technological spillover does not imply that the risk of lock-in into a suboptimal technology is removed, but it does imply that the risk is lower than in the cases where technologies are not interrelated.

The current stage of development in environmentally friendly automotive propulsion is best characterized as uncertain: the development potential of various options is high, yet it is unclear which option is optimal from an environmental and an economic point of view. With development still in research phase, planning techniques and forecasting exercises will only partially reduce the information requirement of pro-active polices. Rather, we argue that the current exploration of diverse technologies and experiments, though possibly enhancing the current uncertainty regarding the future course of the car system, is most desirable to limit the risk of a premature lock-in. By implication, one needs to monitor the trends in technological variety and organizational competition. From an ex post evaluation perspective, our statistical analysis aims to answer whether technological variety and organizational competition have increased over the last two decades.

Our thesis holds that a premature lock-in is most likely avoided if (i) technological variety is high and if (ii) organizational competition is high. A larger technological variety implies a more equally spread in R\&D efforts. This variety contributes to an increased understanding of the technical, environmental, and commercial potentials of different options, as well as to spillovers among the different technologies. Variety will therefore greatly reduce the possibility of a premature lock-in. Organizational competition, next to technological variety, also contributes to the reduction of the risk of premature lock-in. We understand organizational competition as the situation where many players are involved in $R \& D$, which reduces the risk of technological substitution, driven by one or a few dominant actors, into a new yet suboptimal technology.

\section{The measurement of variety}

To assess whether or not current R\&D activities in LEV tend to evolve towards a lock-in within one dominant technology, one requires indicators that characterize technological variety and organizational dynamics. We make use of entropy statistics that provide a general methodology to analyze the variety patterns in frequency distributions [15,27-30]. Entropy statistics have been previously deployed in the analysis of one-dimensional distributions of R\&D activity [31,32]. As a measure of variety, scholars used entropy to characterize the flexibility of portfolios of countries and firms. The higher variety of technologies being explored, the more flexible a firm or country can react to uncertain future developments. 
Other applications of the entropy measure include the application to market shares to indicate market concentration [29]. In our analysis, we apply the entropy measure to two dimensions by taking into account both the distribution of patents among technologies and the distribution of patents among organizations. The basic reasoning holds that the higher the entropy of the frequency distribution of patents in different technologies and different organizations, the higher the technological variety and organizational competition, and the lower the probability of a premature lock-in.

\subsection{Entropy}

In this section, we classify each patent in LEV in a two-dimensional frequency matrix. The $X$-dimension concerns $m$ technologies $(i=1, \ldots, m)$ and the $Y$-dimension concerns $n$ organizations $(j=1, \ldots, n)$. We obtain a two-dimensional frequency matrix $p_{i j}$ describing the frequencies of patents belonging to technology $i$ and organization $j$. Marginal frequencies are obtained by:

$$
\begin{aligned}
& p_{i .}=\sum_{j=1}^{n} p_{i j} \\
& p_{. j}=\sum_{i=1}^{m} p_{i j}
\end{aligned}
$$

The entropy of a distribution of patents among technologies is given by:

$$
H(X)=-\sum_{i=1}^{m} p_{i .} \ln p_{i .}
$$

The value $H(X)$ indicates the technological variety present in the distribution of patents among technologies in the industry as a whole. The distribution is characterized by minimum entropy when one single technology completely dominates R\&D activity, indicating a total lock-in of R\&D into one technology. In this case, the share of one technology equals $100 \%$. Entropy then equals:

$$
H_{\min }(X)=-\sum_{i=1}^{m} 1.00 \ln 1.00=0 .
$$

A distribution is characterized by maximum entropy when all technologies have an equal share in total R\&D activity, i.e., a uniform distribution with frequencies equal $1 / m$. For this distribution, entropy equals:

$$
H_{\max }(X)=-\sum_{i=1}^{m}\left(\frac{1}{m}\right) \ln \left(\frac{1}{m}\right)=-\left(\frac{m}{m}\right) \ln \left(\frac{1}{m}\right)=\ln m
$$

The above derivation of maximum entropy implies that when the total number of technologies $m$ increases over time, the maximum possible entropy would increase as well. 
The marginal increase in maximum entropy resulting from the addition of a new technology is decreasing with the total number of technologies $m$. This property of the entropy formula reflects the notion that the more different technologies are present in a population, the lower the contribution of a new technology to the variety in the population.

Any other distribution yields an entropy value $H(X)$ that lies in between zero and $\ln (m)$. The higher the entropy value of a distribution, the higher the technological variety of $R \& D$ activity in the industry. Entropy provides an indicator of technological variety that can be used to assess whether R\&D activity in an industry tends to lock-in over time. Such a lockin process is indicated when the entropy value of the patent distribution falls over time [15].

Similarly, the entropy of a distribution of patents among organizations is given by:

$$
H(Y)=-\sum_{j=1}^{n} p_{. j} \ln p_{. j}
$$

with $H_{\min }(Y)=0$ and $H_{\max }(Y)=\ln (n)$. The value $H(Y)$ indicates the variety of actors present in the distribution of patents, i.e., organizational competition in R\&D. The distribution is characterized by minimum entropy when one single organization completely dominates R\&D activity, indicating maximum market power (not in terms of sales but in terms of R\&D) and absence of competition. A distribution is characterized by maximum entropy $H(Y)$ when all organizations have an equal share in total R\&D activity, i.e., all $p$ values equal $1 / n$. Maximum entropy corresponds to maximum competition. The maximum entropy for the $Y$-dimension can be derived in the same way as for the $X$-dimension and equals $\ln (n)$.

\subsection{Average conditional entropies}

We argue that premature lock-in is not only a function of technological variety at the industry level but also at the level of individual firms. When organizations individually pursue different technological trajectories, the risk of one organization causing a lock-in is reduced. Diversified R\&D portfolios render organizations more flexible in their strategies to develop one or another environmental friendly propulsion technology.

One can calculate variety by applying the entropy measure to the distribution of patents held by an organization. The entropy of the distribution of patents among $m$ technologies held by organization $j$ is given by [30]:

$$
H\left(X \mid Y_{j}\right)=-\sum_{i=1}^{m}\left(\frac{p_{i j}}{p_{. j}}\right) \ln \left(\frac{p_{i j}}{p_{. j}}\right)
$$

This formula gives the conditional entropy of $X$ given $Y=Y_{j}$ and measures the technological variety of organization $j$. A high value indicates that organization $j$ is exploring a large variety of different technologies, while a low value means that organization $j$ is focusing $R \& D$ on one or few technologies. 
The average conditional entropy of $X$ is defined as the weighted average of conditional entropies of all individual organizations [30]:

$$
\begin{aligned}
H(X \mid Y) & =\sum_{j=1}^{n} p_{. j} H\left(X \mid Y_{j}\right)=-\sum_{i=1}^{n} p_{. j} \sum_{i=1}^{m}\left(\frac{p_{i j}}{p_{. j}}\right) \ln \left(\frac{p_{i j}}{p_{. j}}\right) \\
& =-\sum_{j=1}^{n} \sum_{i=1}^{m} p_{i j} \ln \left(\frac{p_{i j}}{p_{. j}}\right)
\end{aligned}
$$

Note that when one organization completely dominates the industry, $p_{. j}$ equals 1.00 , and we obtain formula (3) from formula (6).

It can be shown that the average conditional entropy $H(X \mid Y)$ has a minimum value of zero when all organizations focus exclusively on one technology, and a maximum value equal to the entropy $H(X)$ when the distribution at organizational levels corresponds exactly to the distribution at industry level. A rising trend in $H(X \mid Y)$ indicates a widening of portfolios of organizations over time, while a falling trend in $H(X \mid Y)$ suggests a trend of more focused portfolios of organizations over time. Note also that the trend in $H(X \mid Y)$ need not follow the trend in $H(X)$. For example, firms may increasingly focus their R\&D activity on one technological option as reflected in a decreasing value of $H(X \mid Y)$, while at the same time the shares of each option at the industry level may equalize, leading to an increasing value of $H(X)$.

In the same way, the conditional entropy of the distribution of patents among $n$ organizations in technology $i$ is given by:

$$
H\left(Y \mid X_{i}\right)=-\sum_{j=1}^{n}\left(\frac{p_{i j}}{p_{i .}}\right) \ln \left(\frac{p_{i j}}{p_{i .}}\right)
$$

This formula gives the conditional entropy of $Y$ given $X=X_{i}$ and measures the variety of organizations active in technology $i$. A high value means that many organizations are more or less equally involved in R\&D in technology $i$ (fierce competition), while a low value means that R\&D activity in technology $i$ is dominated by one or few organizations (little competition).

The average conditional entropy of $Y$ is defined as the weighted average of conditional entropies of all individual technologies, i.e.,

$$
\begin{aligned}
H(Y \mid X) & =\sum_{i=1}^{m} p_{i .} H\left(Y \mid X_{i}\right)=-\sum_{i=1}^{m} p_{i .} \sum_{j=1}^{n}\left(\frac{p_{i j}}{p_{i .}}\right) \ln \left(\frac{p_{i j}}{p_{i .}}\right) \\
& =-\sum_{i=1}^{m} \sum_{j=1}^{n} p_{i j} \ln \left(\frac{p_{i j}}{p_{i .}}\right)
\end{aligned}
$$

Note again that when one technology completely dominates, $p_{i}$. equals 1.00 , and we obtain formula (4) from formula (8). Minimum and maximum values are bounded by zero and $H(Y)$. A rising trend in $H(Y \mid X)$ indicates that technologies are being explored by more and more organizations, while a falling trend indicates that technologies are increasingly explored by a decreasing number of organizations. 


\section{Results}

\subsection{Data}

We obtained results on technological entropy and organizational entropy for two data sets of patents. The first data set covers patents in LEV and the second covers patents in fuel technologies that are used to fuel FCVs. We are aware of the limitations of the use of patents as an indicator of innovative activity. Most patents do not lead to innovations, while most innovations do not draw exclusively on patented knowledge. The use of patents, however, has a number of advantages. Patents are easily obtained from public sources, such as the American-based USPTO (United States Patent and Trademark Office), and can be further analyzed using word queries. And, contrary to the use of R\&D expenditures as an innovation indicator, patents measure outputs rather than inputs of R\&D activity, rendering the use of patents preferable above R\&D expenditures.

All patent counts were extracted from the USPTO database using word queries. Years are assigned to patents according to issue dates. The precise search procedure is described in Ref. [1]. We limited the analysis to the three LEVs $(m=3)$ discussed in Section 2: EV, HEV, and FCV. In the case of competing fuel technologies, we took into account five fuel types to fuel FCVs $(m=5)$ : hydrogen, methanol, conventional, natural gas, and alcohol. Conventional fuels include diesel, gasoline, and LPG. These fuels are classified in one category because of their chemical similarities and their common compatibility with existing energy infrastructure.

A second limitation concerned the organizations considered in the analysis. We limited the analysis to the major patenting organizations $(n=11)$, which were selected as having patented at least once in five different years from 1990 onwards. Seven car manufacturers (DaimlerChrysler, Ford, General Motors, Honda, Mitsubishi, Nissan, and Toyota), two fuel cell production companies (Ballard Power Systems and International Fuel Cells), one oil company (Nippon Mitsubishi Oil), and one gas company (Air Products and Chemicals) met this criterion.

For both data sets, we constructed cumulative annual matrices of patents rather than the conventional annual distributions [1]. Cumulative distributions imply that we calculate the entropy in year $t$ using the frequency distribution of patents obtained in all years before and during year $t$. We use cumulative distributions to underscore the effects of increasing returns in R\&D activity. Lock-in phenomena result from increasing returns to adoption, which are modeled as dependent on all previous adoption decisions [4,9].

\subsection{Low-emission vehicles}

Fig. 1a provides the cumulative number of patents in the three technologies. We use a logarithmic scale (base 10) to show the rate of exponential growth that can be derived from the slope of the curves. A number of observations are made from the cumulative totals. First, the growth in the total number of patents is exponential reflecting the first phase of an S-curve [8]. Second, concerning the relative shares of competing technologies, FCV quickly gained dominance in the eighties, but its exponential growth has been decelerating over time. By contrast, the rate of exponential growth in EV and HEV increased in the nineties as indicated by 


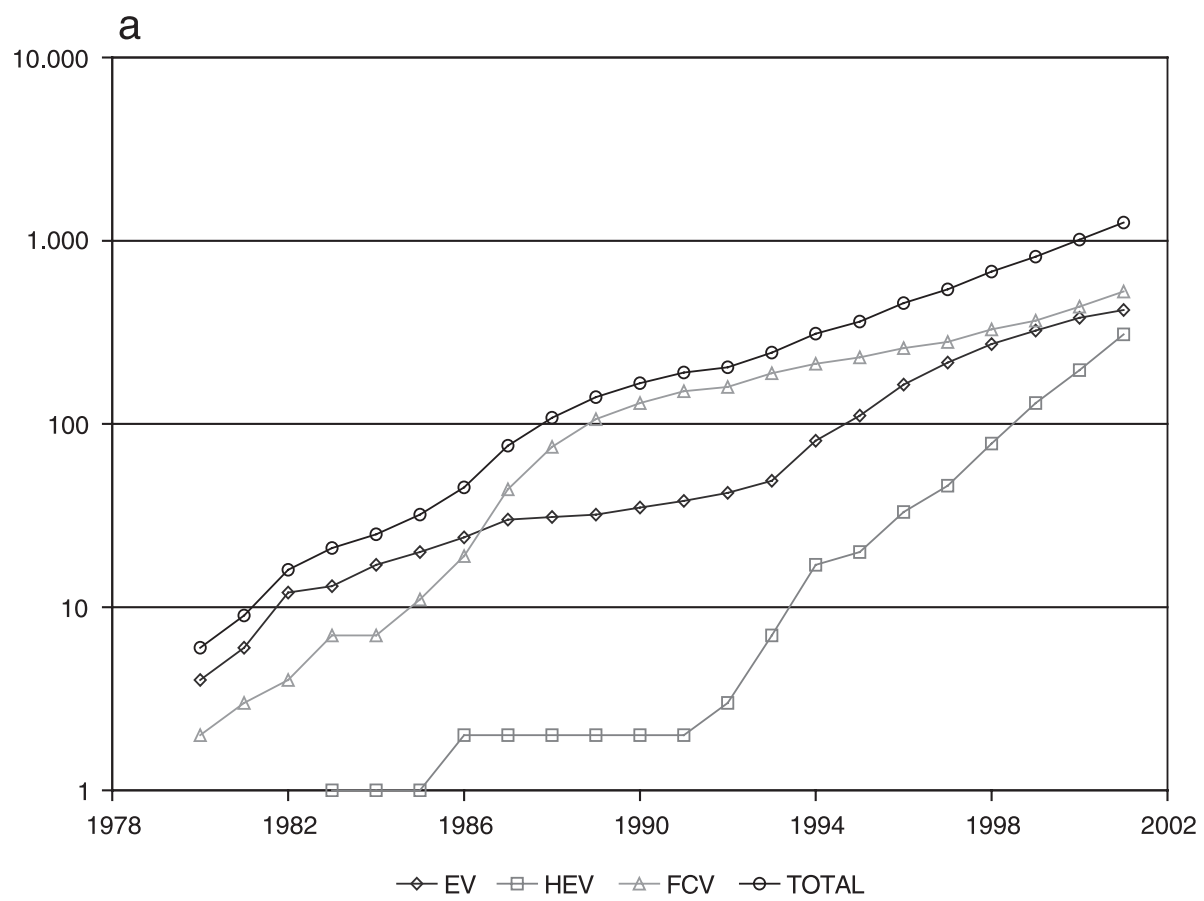

b

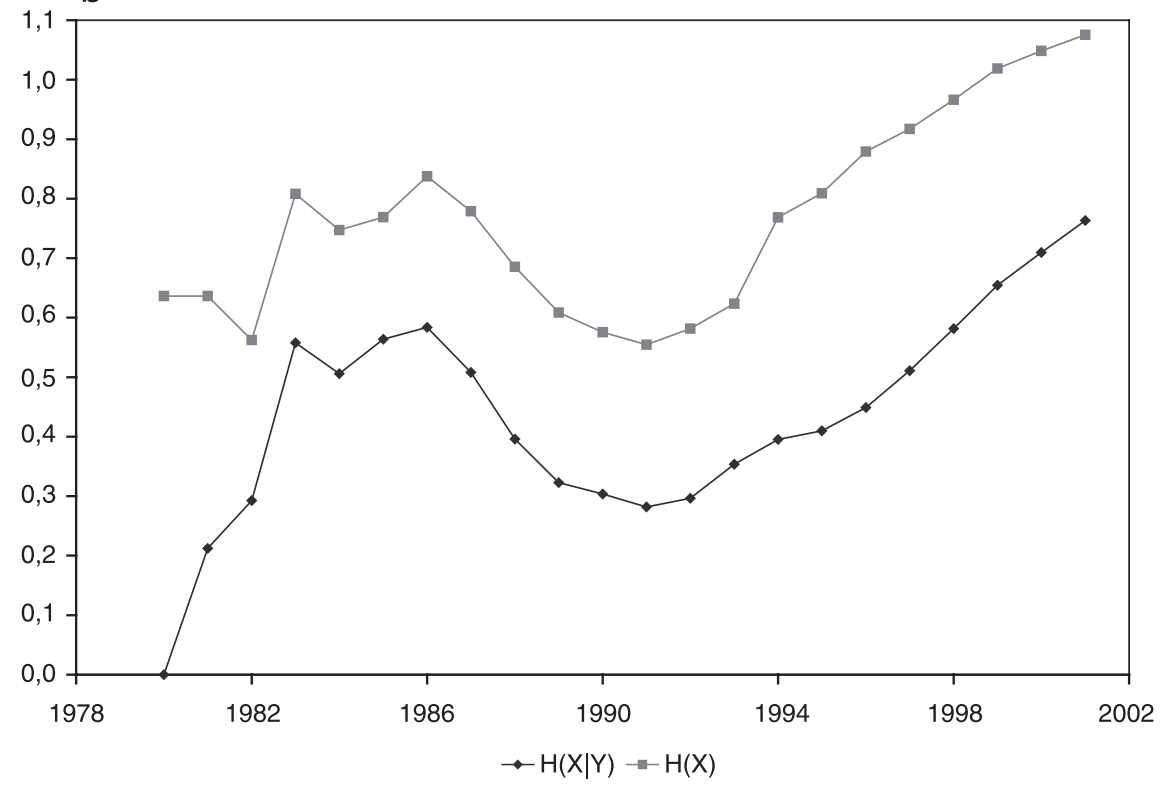

Fig. 1. (a) Cumulative number of patents of all firms per propulsion technology. (b) Entropy of propulsiontechnology distribution at the industry and firm level. (c) Cumulative number of patents in all propulsion technologies per firm (abbreviations: $\mathrm{GM}=$ General Motors; Mitsu=Mitsubishi; DC $=$ DaimlerChrysler; $\mathrm{APC}=$ Air Products and Chemicals; IFC=International Fuel Cells). (d) Entropy of firm distribution at the industry and propulsion technology level. 

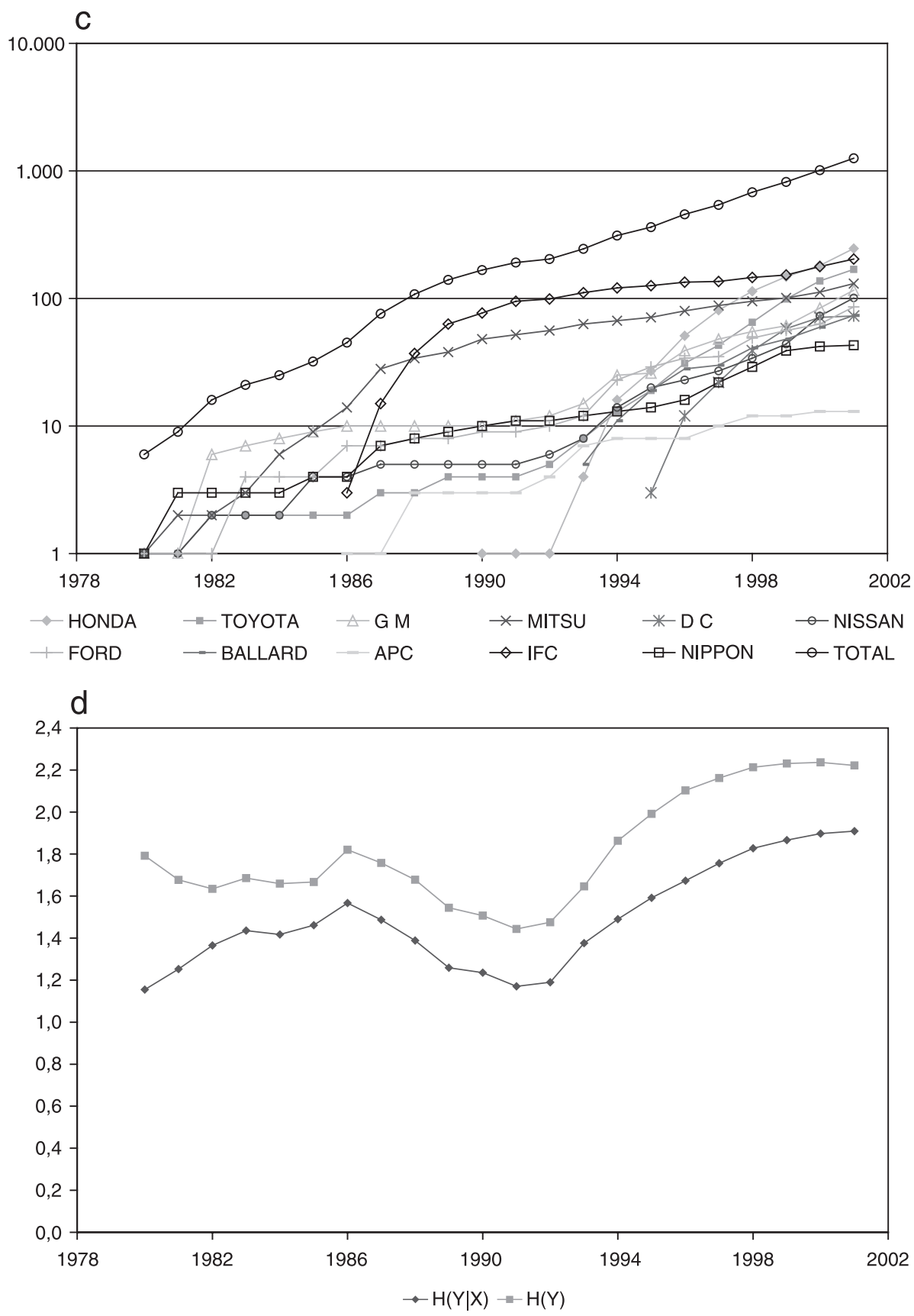

Fig. 1 (continued). 

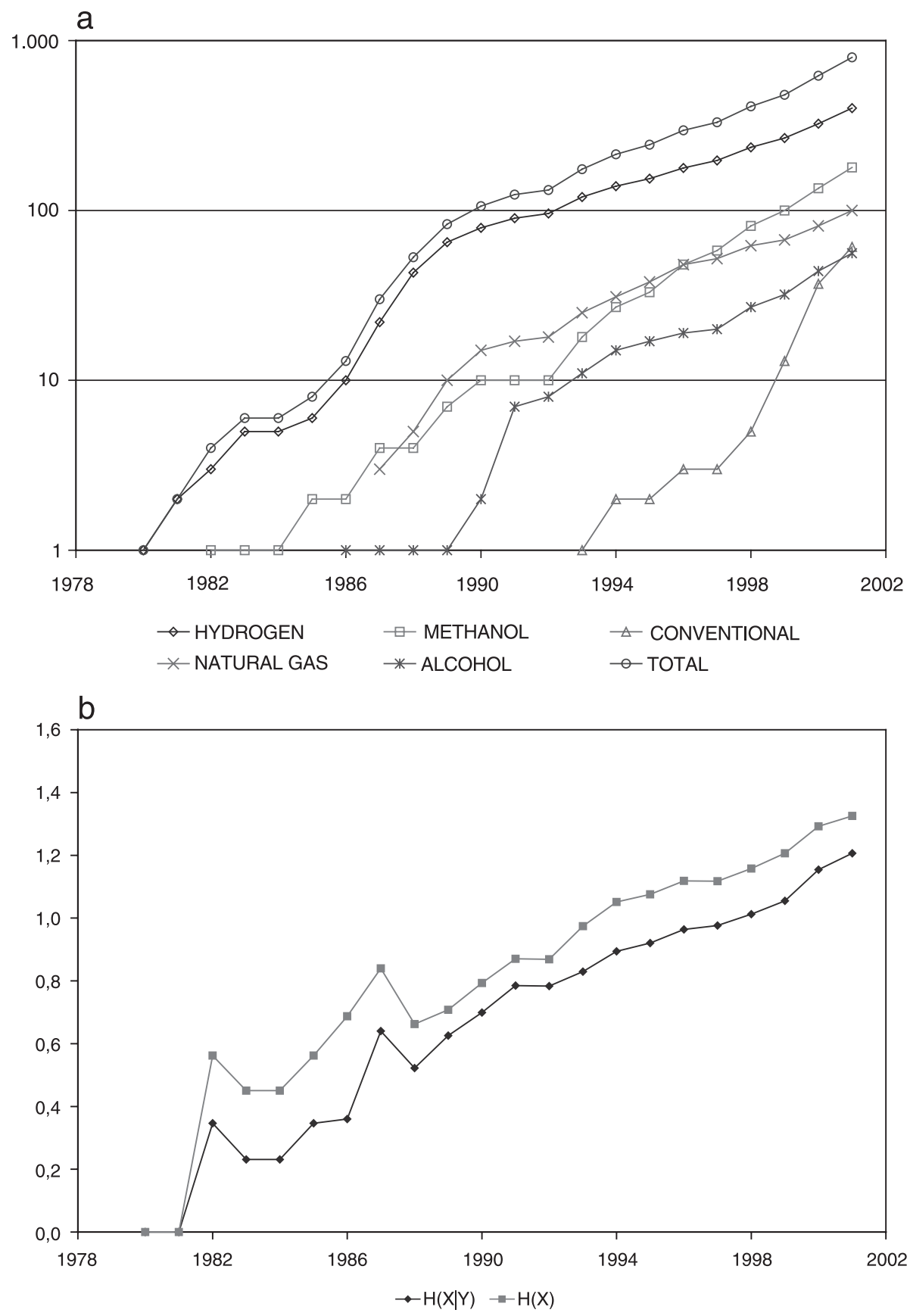

Fig. 2. (a) Cumulative number of patents of all firms per fuel. (b) Entropy of fuel-technology distribution at the industry and firm level. (c) Cumulative number of patents in all fuel technologies per firm. (d) Entropy of firm distribution at the industry and fuel level. 

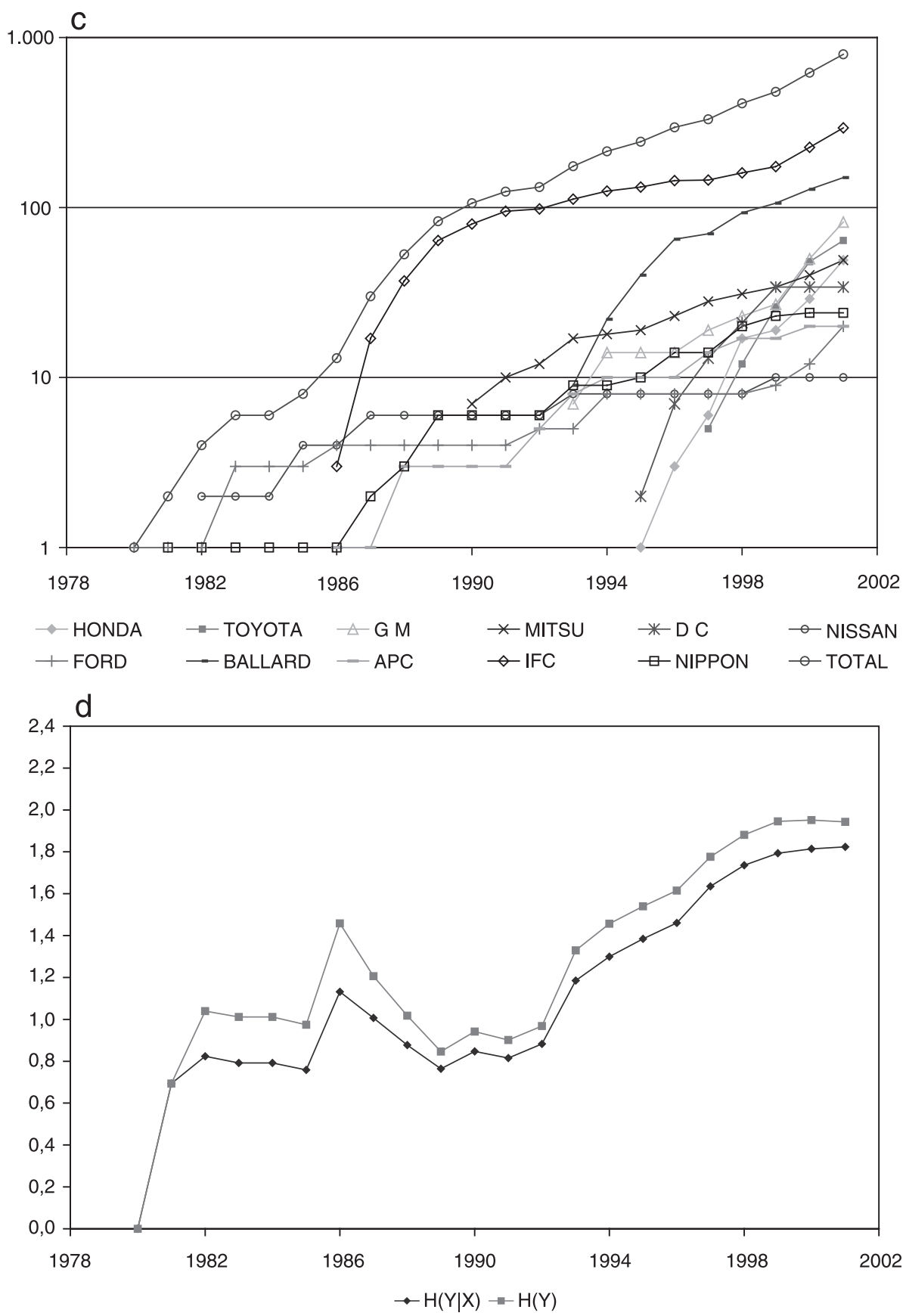

Fig. 2 (continued). 
the steeper slopes. This implies that the momentum shifted from FCV in the eighties to EV and HEV in the nineties. The policy shift in 1990, and in particular the establishment of the Californian Fuel Act, forced actors to pay more attention to EV and HEV is our interpretation. The latter technologies can be developed more easily within a timeframe imposed by the new policy regime compared to FCV, the development of which requires a longer time horizon.

Technological entropy at the industry level $H(X)$ and average conditional technological entropy values at the organization level $H(X \mid Y)$ are shown in Fig. 1b. Note that we use a scale from 0.0 to 1.1 as the maximum possible value of entropy is $\ln (m)=\ln (3)=1.1$. The results show that both the technological entropy and the average conditional technological entropy rose until 1986, then dropping and subsequently rising again after 1992 almost towards the maximum entropy value. The temporary fall in entropy and conditional entropy can be understood as a consequence of the International Fuel Cell consortium dominating patent activity and exclusively focusing its R\&D on FCV. Apart from the temporary drop, the results on conditional entropy show that technological variety in the industry as a whole as well as at the organizational level have steadily increased during the last decades. The increased variety therefore suggests that a premature lock-in at the current stage of development is not to be expected. Organizations increasingly widen their portfolio of patents and hence remain rather flexible in the final adoption decision.

Fig. 1c shows the cumulative number of patents held by the 11 organizations considered in our study. Two organizations dominated in the eighties (International Fuel Cells and, to a lesser extent, Mitsubishi), while two other organizations, Honda and Toyota, exhibit very rapid growth of patents in the nineties. Honda even became the leading organization in 2001 with a cumulative number of 246 patents, while up to 1992 it only held one patent. The rapid growth of patent activity by Honda and Toyota also implied a reorientation in technological activity. Whereas International Fuel Cells dominated the eighties, exclusively focusing on FCV, Honda primarily focused on EV and Toyota primarily focused on HEV.

Fig. 1d shows the organizational entropy at the industry level $H(Y)$ and the average conditional organizational entropy at the technology level $H(Y \mid X)$. Now we use a scale from 0.0 to 2.4 as the maximum possible value of entropy is $\ln (n)=\ln (11)=2.4$ (there are 11 organizations). The resulting pattern is rather unclear during the eighties, but entropy values are steadily increasing in the nineties. This means that competition is increasing at the level of the industry as a whole and at the level of each individual technology. Again, the results suggest that a premature lock-in is not expected to take place in the near future as R\&D activity is highly distributed among many organizations. No single organization has a leading technological position in a particular technology as indicated by their patent record, which suggests that there is currently a low risk of particular companies forcing one technological option on others.

\subsection{Fuel technologies}

We analyzed the second data set fuel technology patents in the same way as the data set on automotive propulsion technologies. Within the class of fuel cell technologies, we analyzed patents associated with five fuel technologies: hydrogen, methanol, conventional, natural gas, and alcohol. Fig. 2a provides the cumulative number of patents in the five fuel technologies. 
First, the results show that the rate of exponential growth decelerates slightly over time. This trend relates to the observations from Fig. 1a that showed the decelerating rate of exponential growth in patents in fuel cell technologies. As argued earlier, we understand this deceleration of R\&D in FCV as a reflection of the rather sudden demand of authorities to introduce LEV in the short-term causing the momentum to shift to EV and HEV. A second observation holds that patent activity in different fuel technologies took off at different dates. Early research concentrated on hydrogen followed by methanol and natural gas. Alcohol took off in the early nineties, while conventional fuels only took off in the late nineties. Again, the latter trend may well be affected by the shift in policy, which demanded a rapid introduction of LEV and consequently opened up conventional fuels, which require little or no investment in infrastructure, as a short-term option.

Technological entropy at the industry level $H(X)$ and average conditional technological entropy values at the organization level $H(X \mid Y)$ are shown in Fig. 2b. Note that we now use a scale from 0.0 to 1.6 as the maximum possible value of entropy is $\ln (m)=\ln (5)=1.6$ (there are five fuel technology classes). The results show that, overall, both the technological entropy and the average conditional technological entropy have risen during the whole period under consideration. Technological variety has steadily increased at the industry level and at the level of individual organizations, reducing the risk of premature lock-in.

Fig. 2c shows the cumulative number of patents by the 11 organizations. The curves are less smooth than in the previous analysis of vehicle technologies in Fig. 1c due to a lower number of observations per organization. One organization dominated during the entire period (International Fuel Cells) while only in the nineties other organizations rapidly increased their patenting activity, in particular, Ballard, General Motors, and again, Honda and Toyota. All these organizations focused primarily on hydrogen and methanol, while Toyota recently patented several inventions in conventional fuels.

Fig. $2 \mathrm{~d}$ shows the organizational entropy at the industry level $H(Y)$ and the average conditional organizational entropy at the fuel level $H(Y \mid X)$. Again, we use a scale from 0.0 to 2.4 as the maximum possible value of entropy is $\ln (n)=\ln (11)=2.4$. The pattern is rather unclear during the eighties for both entropy values, but is steadily increasing in the nineties. This means that organizational competition has increased both in the industry as a whole and at the level of individual fuel technologies. Organizations have widened their R\&D portfolios thus reducing a premature lock-in.

\section{Discussion of results}

R\&D in LEV and fuel technology has shown a consistently growing technological variety and an increase in organizational competition from the nineties onwards. The results suggest that neither a lock-in into one dominant car technology nor into one dominant fuel technology is expected in the near future. The current stage in technological transition is best characterized as an explorative stage in which organizations increasingly explore different technologies and in which technologies are more and more being explored by different organizations. However, there has been a shift in trends of patenting activity in the early 
nineties. The strong focus in the eighties on FCV technology in general, and hydrogen in particular, was a consequence of the dominance of International Fuel Cells consortium, which alone was almost entirely responsible for all $R \& D$ during the period 1986-1990. The emphasis in the eighties on FCV mirrors the long-term time horizon of International Fuel Cells. With the establishment of the Californian Fuel Act in 1990, the relevant time horizon shortened for car manufacturers to a timeframe of 10-20 years.

We found that the policy shift caused three new trends to occur. First, car manufacturers became more heavily involved in R\&D as indicated by the sudden rise in their patenting activity (in particular, General Motors, Honda, and Toyota). Second, the momentum as indicated by the slope of the logarithmic curves, shifted from FCV to EV and HEV. The reorientation reflects the shortening of the relevant time horizon as the latter options can be developed more easily within the current regime in car technology and infrastructure provision. Third, within the class of FCV patents, momentum shifted from hydrogen and natural gas, which require fundamental changes in infrastructure, to methanol and conventional fuels, again reflecting the approaching deadline to introduce LEV.

In our view, the reorientation from FCV to EV and HEV should not be taken to mean that short-term adoption of one of these two technologies would severely block the development of FCV in the longer run. Recall that a large number of innovations that are currently developed within the classes of EV and HEV have important spillover effects on the future development of FCV. Moreover, our results only find a change in emphasis from FCV to EV and HEV, yet also show that patent activity in FCV is still rising exponentially. EV is best viewed as a niche technology for particular purposes (short distance), while HEV can function as a transitional technology that enables car manufacturers to experiment with innovations in various subsystems within the constraints of the current internal combustion engine regime. The rapid rise in R\&D activity in EV and HEV may be more a reflection of the approaching deadlines posed by the Californian Fuel Act rather than a fundamental shift in $R \& D$ orientation in the longer run. This view can be further supported by the fact that the Californian Low Emission Vehicle program only specifies that a small subset of the car park has to meet the new criteria, which still leaves open the options that will be developed for the larger part of the car park in the longer run. The growing variety and competition in automotive propulsion and fuel technologies can be considered as a positive evaluation from a technology policy and environmental policy point of view. A premature lock-in into a technology and/or fuel that may turn out to be suboptimal at a later stage is not expected.

The results obtained above, however, should be handled with care. A number of caveats apply. First, we took patents as innovation output indicators, which are known to be only partially indicative of innovative performance. Not all knowledge is patented and is patentable. Moreover, patents generally differ in relevance for future technological development. Yet, lacking other indicators of importance, we used patent counts to establish cumulative distributions. Given the limitations of patent analysis, future research should include supplementary qualitative research based on interviews with representatives of the major players found in this study. Such methods do not only yield information in its own right, but can also be used to confront the quantitative evidence with the expectations held by industrialists and vice versa. Second, we limited the analysis to three vehicle technologies and 
five fuel technologies. Although we discussed the technological importance of these technologies for future car development, a number of other (sub-)technologies are omitted. For example, we did not take into account the possible technological options within the EV and HEV classes, such as different battery technologies, while some have argued that the variety $R \& D$ activity within these classes is less than optimal [33]. Third, some of the EV patents are of interest for FCV development since the electrical drive train of EV and FCV overlap considerably. A more in-depth analysis of the patents might have led to more patents related to FCVs.

\section{Reflection on policy}

We conclude our article with a reflection on the LEV program that the CARB mandated in 1990, also mandated in a number of other U.S. states at a later stage. This regulatory policy was intended to force firms and other organizations to develop radical new and sustainable car technology. The ambitious goals and medium-term timeframe shifted research to truly innovative solutions rather than to quick and easy incremental improvements in current internal combustion engine technology. Our study provides a number of quantitative indications that the LEV program can indeed be evaluated positively. First, the number of participating firms and their relative share in patenting activity in the nineties suggests that the organizational variety of actors participating in the development of LEV has increased substantially. Second, the technological variety, both at the industry level and the level of individual firms, has also risen consistently after 1990. We argue that both trends have contributed to the development of a variety of options that have in turn helped avoid premature lock-in. What is more, efforts to develop longer-term technologies based on FCV have not been halted but continue to grow exponentially. This result reveals that mediumterm policy still enhances long-term R\&D as car manufacturers expect an extension to current policy in the long run and its application to an increasing share of the car park.

The growth in technological variety and organizational competition therefore coincides with the change in environmental policy that was implemented in 1990. To the extent that the change in technological variety and organizational variety can be related to the establishment of the LEV policy, the demand-pull nature of the regulatory policy has proven effective. By setting new environmental norms, organizations have developed a large variety of options, some of which can be realized within a short term (EV and HEV) while others are focused on a longer term (FCV). As the regulation specified only performance characteristics (zeroemission, energy-efficiency) and not the technical characteristics of the technology, organizations were free to develop technology to meet the new performance standards. This demand-pull strategy of the regulatory government most likely contributed to the growing variety of options in technologies and fuels.

On the extent to which the current dynamics of innovation in LEV under the new policy regime can be generalized to other sectors, in our view, the success of the demand-pull regulatory policy in California does not mean that this type of policy is automatically effective in other sectors. There are at least three factors characterizing the automobile 
industry, as a mature and concentrated industry, that may well have played an important role in the success of the LEV program:

1. Firm size: given the large sizes of firms in the car industry, firms are expected to have both the financial and R\&D capabilities to pursue large R\&D programs [34].

2. Appropriability conditions: car firms are able to protect intellectual property rights by patenting radical new technologies and internalizing knowledge externalities within the company [35].

3. Market structure: coordination of future adoption decisions among car manufacturers, fuel companies, and infrastructure providers is more easily achieved when the number of players in the market is moderate. This raises the likelihood of technological substitution and thus creates incentives to invest in R\&D both individually and within consortia [7].

Incumbent firms thus have both the means and opportunities to develop radical new technologies that meet the new functional requirement demanded by the authorities. Moreover, in the absence of supply-side measures, such as direct R\&D subsidies, the demand-pull strategy of the LEV program also leaves room for new firms to enter the fray.

In other industries characterized by different market structures or appropriability conditions, a demand-pull policy may not be as effective as found in the case of the car industry, for example, when firms are relatively small and lack competencies and resources to engage in radical innovation. Supplementary supply-side policies, including investments in targeted public research institutions and tax incentives for private $\mathrm{R} \& \mathrm{D}$, could be necessary. However, as far as the automobile industry is concerned, the demand-pull policy strategy works rather well. Given the structural similarities between the American and European car industries, policymakers in Europe could learn important lessons from the experiences on the other side of the Atlantic.

\section{References}

[1] P. Godfroij, The Transition Route to Low Emission Vehicles, Department of Innovation Studies, Utrecht University, Utrecht, 2002.

[2] Q. Robert, Riley Enterprises, electric and hybrid vehicles: an overview of the benefits, challenges, and technologies, Technical Paper, June, Available at: http://www.Rqriley.Com, 1999.

[3] U.S. Department of Energy, Hybrid Electric Vehicle Program, Available at: http:/www.ott.doe.gov/hev/ what.html, 2001.

[4] W.B. Arthur, Competing technologies, increasing returns, and lock-in by historical events, Econ. J. 99 (1989) $116-131$.

[5] P.A. David, The economics of qwerty, Am. Econ. Rev. Pap. Proc. 75 (1985) 332-337.

[6] D. Foray, The dynamic implications of increasing returns: technological change and path dependent inefficiency, Int. J. Ind. Organ. 15 (6) (1997) 733-752.

[7] E. Bruckner, W. Ebeling, M.A.J. Montano, A. Scharnhorst, Nonlinear stochastic effects of substitution —an evolutionary approach, J. Evol. Econ. 6 (1) (1996) 1-30.

[8] A. Grubler, N. Nakicenovic, D.G. Victor, Dynamics of energy technologies and global change, Energy Policy 27 (5) (1999) 247-280. 
[9] W.B. Arthur, Competing technologies and lock-in by historical events: the dynamics of allocation under increasing returns, IIASA Working Paper WP-83-90, 1983, Laxenburg, Austria.

[10] P. Mulder, H.L.F. De Groot, M.W. Hofkes, Economic growth and technological change: a comparison of insights from a neo-classical and an evolutionary perspective, Technol. Forecast. Soc. Change 68 (2) (2001) $151-171$.

[11] R. Cowan, S. Hulten, Escaping lock-in: the case of the electric vehicle, Technol. Forecast. Soc. Change 53 (1) (1996) 61-79.

[12] R. Axelrod, W. Mitchell, R.E. Thomas, D.S. Bennett, E. Bruderer, Coalition-formation in standard-setting alliances, Manage. Sci. 41 (9) (1995) 1493-1508.

[13] J. Islas, Getting round the lock-in in electricity generating systems: the example of the gas turbine, Res. Policy 26 (1) (1997) 49-66.

[14] D. Levinthal, The slow pace of rapid technological change: gradualism and punctuation in technological change, Ind. Corp. Change 7 (2) (1998) 217-247.

[15] K. Frenken, P.P. Saviotti, M. Trommetter, Variety and niche creation in aircraft, helicopters, motorcycles and microcomputers, Res. Policy 28 (5) (1999) 469-488.

[16] P. Menanteau, H. Lefebvre, Competing technologies and the diffusion of innovations: the emergence of energy-efficient lamps in the residential sector, Res. Policy 29 (3) (2000) 375-389.

[17] J.M. Dalle, Heterogeneity vs. externalities in technological competition: a tale of possible technological landscapes, J. Evol. Econ. 7 (4) (1997) 395-413.

[18] P.A. David, Path-dependence and predictability in dynamic systems with local network externalities: a paradigm for historical economics, in: D. Foray, C. Freeman (Eds.), Technology and the Wealth of Nations, Pinter, London, 1993, pp. 208-231.

[19] D.S. Scharfstein, J.C. Stein, Herd behavior and investment, Am. Econ. Rev. 80 (3) (1990) 465-479.

[20] S. Bikhchandani, D. Hirshleifer, I. Welch, Learning from the behavior of others: conformity, fads, and informational cascades, J. Econ. Perspect. 12 (3) (1998) 151-170.

[21] W.J. Abernathy, The Productivity Dilemma: Roadblock to Innovation in the Automobile Industry, Johns Hopkins Univ. Press, Baltimore, MD, 1978.

[22] W.J. Abernathy, J.M. Utterback, Patterns of industrial innovation, Technol. Rev. 50 (1978) 41-47.

[23] J.M. Utterback, Mastering the Dynamics of Innovation, Harvard Business School Press, Cambridge, MA, 1994.

[24] S. Klepper, Industry life-cycles, Ind. Corp. Change 6 (1997) 145-182.

[25] E.W. Constant, The Origins of the Turbojet Revolution, Johns Hopkins Univ. Press, Baltimore, MD, 1980.

[26] R. Cowan, Nuclear-power reactors - a study in technological lock-in, J. Econ. Hist. 50 (3) (1990) 541-567.

[27] P.P. Saviotti, Information, variety and entropy in technoeconomic development, Res. Policy 17 (2) (1988) $89-103$

[28] L. Leydesdorff, The Challenge of Scientometrics. The Development, Measurement, and Self-Organization of Scientific Communications, DSWO Press, Leiden University, Leiden, 1995.

[29] H. Theil, Economics and Information Theory, North-Holland, Amsterdam, 1967.

[30] H. Theil, Statistical Decomposition Analysis, North-Holland, Amsterdam, 1972.

[31] F. Kodama, Technological entropy dynamics: towards a taxonomy of national R\&D efforts, in: J. Sigurdson (Ed.), Measuring the Dynamics of Technological Change, Pinter, London, 1990, pp. 146-147.

[32] H. Grupp, The concept of entropy in scientometrics and innovation research. An indicator for institutional involvement in scientific and technological developments, Scientometrics 18 (1990) 219-239.

[33] R.N. McGrath, Effects of incumbency and R\&D affiliation on the legitimation of electric vehicle technologies, Technol. Forecast. Soc. Change 60 (3) (1999) 247-262.

[34] W.M. Cohen, S. Klepper, A reprise of size and R\&D, Econ. J. 106 (437) (1996) 925-951.

[35] S. Breschi, F. Malerba, L. Orsenigo, Technological regimes and Schumpeterian patterns of innovation, Econ. J. 110 (463) (2000) 388-410. 